\title{
Fasciola hepatica: tanısında endoskopik retrograd kolanjiyopankreatografi: tek merkez deneyimi
}

\author{
Endoscopic retrograde cholangiopancreatography for the diagnosis of Fasciola hepatica: a single-center
} experience

Muhammet Yener AKPINAR, Bülent ÖDEMIŞ, Selçuk DişiBEYAZ, Erkin ÖZTAŞ, Zeki Mesut Yalın KILIÇ, Ufuk Barış KUZU, Orhan ÇOŞKUN, Adem AKSOY, Vedat ERKAN, Ertuğrul KAYAÇETIN

Türkiye Yüksek Ihtisas Eğitim ve Araştırma Hastanesi, Gastroenteroloji Kliniği, Ankara

Giriş ve Amaç: Literatürde endoskopik retrograd kolanjiyopankreatografi ile tanısı konulan Fasciola hepatica olguları daha çok vaka sunumu olarak bildirilmektedir. Çalışmamızın amacı kliniğimizde endoskopik retrograd kolanjiyopankreatografi ile tanısı konan Fasciola hepatica hastalarımızın demografik, klinik ve laboratuvar özelliklerini ortaya koymaktır. Gereç ve Yöntem: Türkiye Yüksek Ihtisas Eğitim ve Araştırma Hastanesi endoskopik retrograd kolanjiyopankreatografi ünitesinde 2007-2016 yılları arasında endoskopik retrograd kolanjiyopankreatografi yapilan toplam 15.785 hasta retrospektif olarak tarandi. Fasciola hepatica tanisinin endoskopik retrograd kolanjiyopankreatografi esnasında parazitin endoskopik görülmesi ile konulduğu 17 hasta çalışmaya alındı. Bulgular: Çalışmamıza toplam 17 hasta (15 erkek, 2 kadın) alındı. Yaş ortancası 45'di. Karın ağrısı hastaların en sık izlenen başvuru şikayetiydi. Hastalarda eozinofili görülme sıklığ \%87 olarak bulundu. Endoskopik retrograd kolanjiyopankreatografi esnasında çıkarılan ortanca parazit sayısı 2'di. Sonuç: Kolestaz kliniği ile başvuran bir hastada anamnezde su teresi yeme öyküsünün olması, eozinofili varlığı, Fasciola hepatica şüphesini artıran bulgulardır. Hastaların safra yollarında birden fazla parazit olabilir; bu nedenle endoskopistin tek parazit çıktıktan sonra da dikkatli bir şekilde safra yollarını değerlendirmesi önemlidir.

Anahtar Kelimeler: Endoskopik retrograd kolanjiyopankreatografi, Fasciola hepatica

\section{GIIRIŞ}

Fasioliazis, Fasciola hepatica veya Fasciola gigantica trematodları tarafından oluşturulan bir enfeksiyon hastalığıdır. Hastalık tüm dünyada görülür; ülkemizin de içinde olduğu bazı bölgelerde ise endemiktir. Dünya genelinde 2,4 milyon insan hastalıktan etkilenmektedir. Koyun, keçi, sığır ve tavşan gibi otçul hayvanların paraziter hastalığı olan Fasciola hepatica kontamine su veya bitkilerin yenilmesi ile insanlara bulaşır. Parazit yaprak şeklinde olup karaciğere trofizm gösterir, nihai yerleşim yeri ise biliyer sistemdir (Resim 1). Literatürde endoskopik retrograd kolanjiyopankreatografi (ERCP) ile tanısı konulan Fasioliazis olguları daha çok vaka sunumu olarak bildirilmektedir (1). Bu konuyla ilgili yapılan çalışmalar ise sınırlıdır. Çalışmamızın amacı ERCP ile tanısı konan Fasciola hepatica hastalarımızın demografik, klinik ve laboratuvar özelliklerini ortaya koymaktır.

Akpınar MY, Ödemiş B, Dişibeyaz S, et al. Endoscopic retrograde cholangiopancreatography for the diagnosis of Fasciola hepatica: a single-center experience. Endoscopy Gastrointestinal 2016;24:47-50.
Background and Aims: Fasciola hepatica diagnosed with endoscopic retrograde cholangiopancreatography has usually been mentioned in case reports in the literature. The aim of our study is to demonstrate the demographic, clinical, and laboratory features of Fasciola hepatica patients diagnosed with endoscopic retrograde cholangiopancreatography in our clinic. Material and Methods: A total of 15.785 patients, in whom endoscopic retrograde cholangiopancreatography was performed at Türkiye Yüksek Ihtisas Training and Research Hospital in 2007-2016, were screened retrospectively. Seventeen patients diagnosed with Fasciola hepatica, which was seen through endoscopic examination, were included in the study. Results: A total of 17 patients (15 males and 2 females) were included in our study. The median age was 45 . Abdominal pain was the most frequent patient complaint. The frequency of eosinophilia was $87 \%$. The median number of parasites extracted during endoscopic retrograde cholangiopancreatography was two. Conclusion: Eating watercress and the presence of eosinophilia are findings that increase the suspicion of Fasciola hepatica in a patient admitted to hospital with cholestasis. The biliary tract of patients may have more than one parasite. Therefore, it is important for the endoscopist to evaluate the biliary tract carefully after one parasite is seen.

Key words: Endoscopic retrograde cholangiopancreatography, Fasciola hepatica

\section{GEREÇ ve YÖNTEM}

Türkiye Yüksek Ihtisas Eğitim ve Araştırma Hastanesi ERCP ünitesinde 2007-2016 tarihleri arasında ERCP yapilan toplam 15.785 hasta retrospektif olarak tarandı. ERCP esnasinda parazitin endoskopik görülmesi ile fasioliazis tanısı konulan 17 hasta çalışmaya alındı. Fasioliazis tanısı konulan hastaların tümüne klinik, laboratuvar ve görüntüleme yöntemleri esas alınarak biliyer sistem patolojisi ön tanısıyla ERCP yapılmıştı. Fasioliazis tanısı olan hastaların demografik, klinik ve laboratuvar özelliklerine hastaların dosyalarından ve bilgisayar veri tabanından ulaşıldı.

\section{BULGULAR}

Çalısmamıza toplam 17 hasta alındı. Hastaların 15 tanesi kadın 2 tanesi erkekti. Yaş ortancaları 45 olup en genç hasta 9 


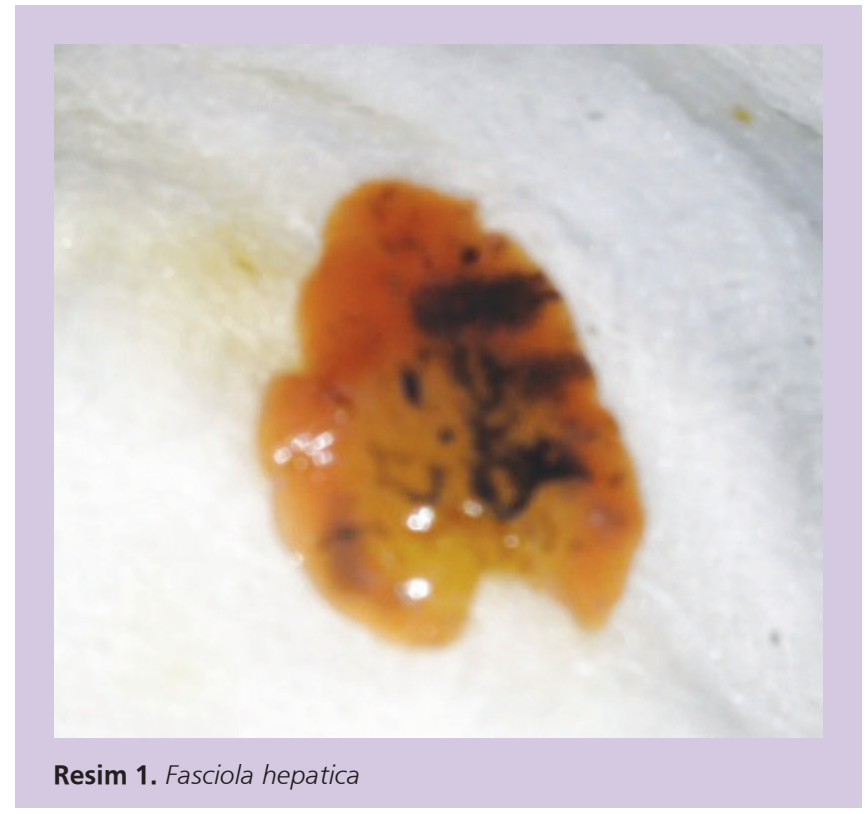

yaşında, en yaşlı hasta ise 75 yaşındaydı. Hastaların başvuru esnasında ikamet ettikleri yerleşim yerleri incelendiğinde 10 hastanın il merkezinde 7 hastanın ise ilçede ikamet ettikleri tespit edildi. Hastaların klinikte başvuru şikayetleri farklılık göstermekteydi. Tüm hastalarda karın ağrısı vardı ve bu en sık izlenen başvuru şikayetiydi. 4 hastada karın ağrısıyla beraber ateş varken bir hastada karın ağrısıyla beraber sarılık izlendi. ERCP öncesinde 5 hastaya endoskopik ultrasonografi (EUS), 4 hastaya da manyetik rezonan kolanjiyopankreatografi (MRCP) yapılmıştı. EUS sadece bir hastada hiperekojen, tübüler görünümlü ve hareketli oluşum şeklinde yaptığı tanımlamayla Fasciola hepatica'ya en yakın tanıyı verdi. Diğer 4 hastada ise EUS, koledok içinde ekojenite olarak raporland. MRCP uygulanan 4 hastanın sadece birinde dolum defekti vardi; tüm hastalarda koledok dilateydi (Tablo 1).

ERCP esnasında hastalardan farklı sayılarda parazit çıkarıldı. Ortanca çıkarılan parazit sayısı 2 idi. Parazitlerin hepsi taş balonu yardımıyla çıkarılırken hiçbir hastada basket ve papiller balon dilatasyon ihtiyacı olmadi. Hastaların laboratuvar verileri heterojendi. En dikkat çeken bulgu eozinofili olup bir hastada 2.490 değeri elde edildi; bununla beraber ortanca eozinofili değeri 575 olarak bulundu (Tablo 2). Eozinofili 17 hastanin 14 tanesinde vardı (\%82). Alkalen fosfataz (ALP) 10 hastada yüksekti (\%58). Gama glutamil transpeptidaz 7 hastada yüksekti (\%41). Total bilirubin 6 hastada, direk bilirubin ise 10 hastada yüksekti (sirayla \%35 ve \%58).

\section{TARTIŞMA}

Fasioliazis özellikle gelişmekte olan ülkelerde görülen paraziter bir hastalıktır (2). Etkenlerden Fasciola hepatica dünyada yaygın olarak görülürken Fasciola gigantica daha çok tropik bölgelerde izlenir. Enfeksiyon Merkez ve Güney Amerika, Avrupa (özellikle Portekiz, İspanya ve Türkiye) ve Asya'da endemiktir (3). Parazit primer olarak otçul hayvanları etkiler. Insanlar ise rastlantısal konaktır. Fasciola hepatica'nın yumurtaları hayvanların enfekte dışkıları ile dışarı atılır. Yumurtaların canlı kalabilmeleri için sulu bir ortama ihtiyaçları var-

\begin{tabular}{|c|c|}
\hline Değişken & Sayı \\
\hline Yaş & $45(9-75)$ \\
\hline Cinsiyet (Erkek/Kadın) & $2 / 15$ \\
\hline Yaşadığı Yer (Il/Illçe) & $10 / 7$ \\
\hline \multicolumn{2}{|l|}{ Şikayet } \\
\hline Karın ağrısı & 17 \\
\hline Sarılık & 1 \\
\hline Ateş & 4 \\
\hline Çıkarılan Fasciola sayısı & $2(1-4)$ \\
\hline \multicolumn{2}{|l|}{ Görüntüleme } \\
\hline EUS & 5 \\
\hline MRCP & 4 \\
\hline
\end{tabular}

EUS: Endoskopik ultrasonografi. MRCP: Manyetik rezonans kolanjiopankreatografi.

\section{Tablo 2. Hastaların laboratuvar verileri}

\begin{tabular}{|ll}
\hline Değişken & Sayı \\
\hline Hemoglobin (gr/dl) & $12.9(9.6-14.7)$ \\
\hline Lökosit $\left(x 10^{\wedge} 3 / \mathrm{uL}\right)$ & $8.800(4.700-17.960)$ \\
\hline Platelet $\left(x 10^{\wedge} 3 / \mathrm{uL}\right)$ & $194.000(129.000-420.000)$ \\
\hline Nötrofil (x10^3/uL) & $5.805(1.900-9.350)$ \\
\hline Eosinofil (x10^3/uL) & $575(140-2490)$ \\
\hline ALT (U/L) & $23.5(9-475)$ \\
\hline AST (U/L) & $25.5(14-494)$ \\
\hline GGT (U/L) & $48.5(13-420)$ \\
\hline ALP (U/L) & $155(91-407)$ \\
\hline Total bilirubin (mg/dl) & $0.59(0.39-3.43)$ \\
\hline Direk bilirubin (mg/dl) & $0.29(0.09-3.15)$ \\
\hline Sedimentasyon (mm/saat) & $29(12-85)$ \\
\hline CRP (mg/L) & $1.5(0.28-29.7)$ \\
\hline
\end{tabular}

ALT: Alanin aminotransferaz. AST: Aspartat aminotransferaz. GGT: Gama glutamil transpeptidaz. ALP: Alkalen fosfataz. CRP: C- reaktif protein 


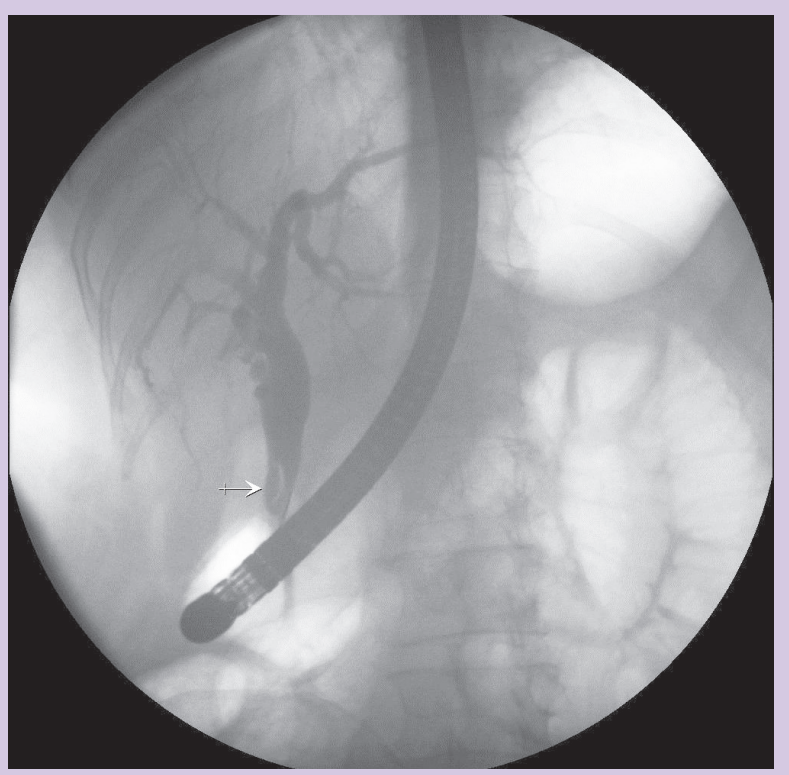

Resim 2. Fasciola hepatica'ya bağlı dolum defektinin kolanjiyogram görünümü.

dır. Yumurtalar içinde oluşan mirasidyumlar uygun ortamda dışarı çıkarlar. Mirasidyum daha sonra ara konak olan tatlı yumuşakçalara girer. Yumuşakçalar içinde mirasidyumlardan serkaryalar oluşur. Serkaryalar su yüzeyinde veya su dibinde de kistleșebilir ve metaserkaryalar meydana gelir. Metaserkarya olarak adlandırıla dönem enfektiftir. Parazit insanlara en sık bulaş yolu su teresi yenilmesiyle veya enfekte suların içilmesiyle oluşur (4). Kalın bağırsağa ulaşan parazit sıklıkla hepatik fleksuradan kolonu terk edip karaciğere ulaşır.

Fasciola hepatica enfeksiyonu birbirinden farklı klinik ve laboratuar bulgularıyla karakterli iki döneme ayrılabilir (5). Akut faz karaciğer parankimi etkilenirken kronik dönemde parazitin esas yerleşim yeri biliyer sistemdir. Metaserkaryaların ağız yolu ile alınmasından yaklaşık 1-3 ay sonra akut faz ortaya çıkar. Bu faz, parazitin karaciğer parankiminde ilerleyişine bağlı oluşan ateş, sağ üst karın ağrısı, iştahsızlık, bulantı, ürtiker, eozinofili ve transaminazlarda artışla karakterizedir $(6,7)$. Hemobili veya subkapsüler kanama da akut dönemde nadiren görülebilir (8). Kronik veya biliyer fazda safra yollarına yerleşen parazit tıpkı taş gibi hastalarda biliyer kolik, sarllık ve/veya kolanjit tablosu ile kendini gösterebilir. Biliyer sisteme yerleşen parazit yılar boyu asemptomatik olarak da kalabilir. Bazı hastalarda parazit tanısı akut pankreatit sonrası da konulmuştur (9).

Anamnez, laboratuvar ve görüntüleme yöntemlerinde Fasciola hepatica tanısını koymak için önemli ipuçları vardır. Hastaların anamnezlerinde su teresi yeme öyküsü Fasciola hepatica şüphesini artırır (10). Eozinofili varlı̆̆ı klinisyen için dikkat çekicidir. Ülger ve arkadaşlarının yaptıkları çalışmada eozinofili sıklığı \%79 olarak bulunmuştur (11). Bizim çalışmamızda ise eozinofili sıklığı \%82 olarak izlenmiştir. Görüntüleme yöntemleri de fasioliazis tanısı için oldukça önemlidir. Transabdominal ultrasonografi fasciola hepatica için spesifik değildir, bununla beraber safra yollarında dilatasyon ve bazen koledokta hiperekojen lezyonlar görülebilir (12). Bilgisayarlı tomografi akut fazdaki hastaları tanımada daha duyarlıdır. Karaciğer kapsülünden parankime doğru uzanan lineer hipodens görünüm akut fazdaki hastaların tipik görüntüsü olarak kabul edilir $(13,14)$. Endoskopik ultrasonografi biliyer sistem hastalıkları ayırıcı tanısında değerli bir görüntüleme yöntemi olup parazit burada kendini hareketli, hiperekojen oluşum olarak gösterebilir. EUS ve MRCP kronik fazdaki hastaların tanısında daha çok fayda sağlar (Resim 1) $(15,16)$. Kronik fazda olan hastalarda ERCP ilk tercihtir. ERCP ile hem parazitin kesin tanısı hem de tedavisi mümkün olur $(17,18)$ (Resim 2,3).

Medikal tedavide ilk sırada triklabendazol yer alır. Bu ilaç ilk olarak 1986 yılında insanlarda başarıyla kullanılmaya başlanmıştır. Kullanım şekli tek doz 10-12 mg/kg ya da 12 saat arayla günde 2 doz olarak kabul edilir. Efektivitesi \%80-90'larda olan ve iyi tolere edilen bu ilacin en sik rastlanan yan etkileri bulantı, kusma ve karın ağrısıdır (19). Diğer medikal tedavi seçenekleri arasında nitazoksanid, albendazol yer almaktadır.

Sonuç olarak kolestaz kliniği ile başvuran bir hastada anamnezde su teresi yeme öyküsünün olması, eozinofili varllğı, EUS'da biliyer sistemde hiperekojen, hareketli ve tübüler oluşumların görülmesi Fasciola hepatica şüphesini artıran bulgulardır. Hastaların safra yollarında birden fazla parazit olabilir; bu nedenle endoskopistin tek parazit çıktıktan sonra da dikkatli bir şekilde safra yollarını değerlendirmesi önemlidir.

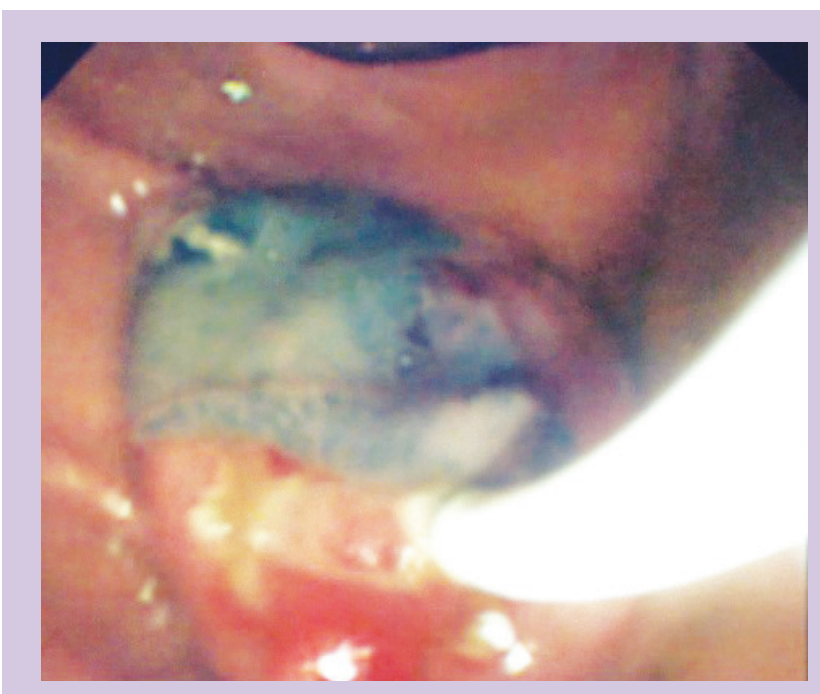

Resim 3. Fasciola hepatica'nın taş balonla koledoktan çıkarılması. 


\section{KAYNAKLAR}

1. Lazo Molina L, Garrido Acedo R, Cárdenas Ramírez B, et al. Endoscopic removal by ERCP of Fasciola hepatica alive: two case reports and review of the literature. Rev Gastroenterol Peru 2013;33:75-81.

2. Mas-Coma S. Epidemiology of fascioliasis in human endemic areas. J Helminthol 2005;79:207-16.

3. Mas-Coma S, Valero MA, Bargues MD. Chapter 2. Fasciola, lymnaeids and human fascioliasis, with a global overview on disease transmission, epidemiology, evolutionary genetics, molecular epidemiology and control. Adv Parasitol 2009; 69:41-146.

4. Chan CW, Lam SK. Diseases caused by liver flukes and cholangiocarcinoma. Baillieres Clin Gastroenterol 1987;1:297-318.

5. Alatoom A, Cavuoti D, Southern P, et al. Fasciola hepatica Infection in the United States. Lab Med 2008;39:425-8.

6. Aksoy DY, Kerimoglu U, Oto A, et al. Fasciola hepatica infection: Clinical and computerized tomographic findings of ten patients. Turk J Gastroenterol 2006;17:40-5.

7. Mas-Coma S, Agramunt VH, Valero MA. Neurological and ocular Fascioliasis in Humans. Adv Parasitol 2014;84:27-149.

8. Kaya M, Beştaş R, Cetin S. Clinical presentation and management of Fasciola hepatica infection: singlecenter experience. World J Gastroenterol 2011;17:4899-904.

9. Sezgin O, Altıntaş E, Tombak A, et al. Fasciola hepatica induced acute pancreatitis: report of two cases and review of the literature. Turk J Gastroenterol 2010;21:183-7.
10. Ashrafi K, Bargues MD, O'Neill S, Mas-Coma S. Fascioliasis: a worldwide parasitic disease of importance in travel medicine. Travel Med Infect Dis 2014;12:636-49.

11. Ulger BV, Kapan M, Boyuk A, et al. Fasciola hepatica infection at a University Clinic in Turkey. J Infect Dev Ctries 2014;8:1451-5.

12. Van Beers B, Pringot J, Geubel A, et al. Hepatobiliary fascioliasis: noninvasive imaging findings. Radiology 1990;174:809-10.

13. Dusak A, Onur MR, Cicek M, et al. Radiological imaging features of Fasciola hepatica infection - A pictorial review. Clin Imaging Sci 2012;2:2.

14. Patel NU, Bang TJ, Dodd GD 3rd. CT findings of human Fasciola hepatica infection: case reports and review of the literature. Clin Imaging 2016;40:251-5.

15. Sezgin O, Altintaş E, Dişibeyaz S, et al. Hepatobiliary fascioliasis: clinical and radiologic features and endoscopic management. J Clin Gastroenterol 2004;38:285-91.

16. Behzad C, Lahmi F, Iranshahi M, et al. Finding of biliary fascioliasis by endoscopic ultrasonography in a patient with eosinophilic liver abscess. Case Rep Gastroenterol 2014;8:310-8.

17. Lazo Molina L, Garrido Acedo R, Cárdenas Ramírez B, et al. Endoscopic removal by ERCP of Fasciola hepatica alive: two case reports and review of the literature. Rev Gastroenterol Peru 2013;33:75-81.

18. Sayilir A, Ödemis B, Köksal AS, et al. Image of the month: Fasciola hepatica as a cause of cholangitis. Am J Gastroenterol 2012;107:655.

19. López-Vélez R, Domínguez-Castellano A, Garrón C. Successful treatment of human fascioliasis with triclabendazole. Eur J Clin Microbiol Infect Dis 1999;18:525-6. 